\title{
The Benefits of Automatic Data Collection in the Fresh Produce Supply Chain
}

\author{
Ryan Charles Panos and Tali Freed
}

\begin{abstract}
The potential for RFID based systems to improve the safety and efficiency of a supply chain with rapidly decaying products and strict health standards is creating pressure to adopt RFID in several agricultural industries. A handful of fresh produce industry leaders currently participate in mandated pilot projects, while the industry as a whole is still intimidated by the perceived cost of RFID. Therefore in this study we attempt to validate the correlation between performance and automated data collection, paving the way to economic justification of investment in data collection technologies, such as barcode and RFID.

The majority of product in this industry is identified and tracked using pallet barcode labels at the more progressive facilities, or facility-specific manual identification methods at the less advanced facilities. Most fresh produce facilities in the US have minimal information systems capabilities, and most of their logistics operations are documented on paper only.

Thus the form of Automated Data Collection (ADC) used in the more advanced facilities is Barcode-based. This study compares facilities that use ADC with those that do not. Significant advantages of using ADC are found in many areas, especially in product spoilage, administrative labor and space utilization.
\end{abstract}

\section{INTRODUCTION}

$\mathrm{L}$ egislation mandating the ability to trace fresh produce from the field to the retail shelf [1] has been considered an added cost to the fresh produce supply chain. However, some systems used in produce facilities not only comply with these regulations but also collect additional information that leads to internal efficiency improvements. This is a study of these methods and their benefits to fresh produce cold storage facilities.

The fresh produce industry is currently trying to use RFID, mainly to comply with mandates. Our survey and general familiarity with this industry indicate that the majority of the fresh produce industry leadership does not believe that the benefits of RFID outweigh its cost. The facilities that ship RFID tagged items to Wal*Mart and other grocery store chains limit RFID tagging to these shipments only - typically the minority of their volume. The majority of the product is identified and tracked using pallet barcode labels at the more progressive facilities, or facilityspecific manual identification methods at the less advanced facilities. Most fresh produce facilities in the US have minimal information systems capabilities, and most of their logistics operations are documented on paper, as described below.

Many produce handling facilities comply with the new traceability laws by manually associating their outgoing sales receipts to their receiving tickets from the field. This method complies with the law but offers very little additional benefit to the processes within the facility. More advanced systems acquire valuable process data on every pallet by printing a barcode to represent this pallet number on a pallet tag and scanning this barcode during processing steps in the facility. This form of automatic data collection has been claimed by several industry leaders to lead to efficiency improvements. Attempting to measure these improvements is the primary focus of our study.

In this paper we show that ADC using Pallet BARCODE leads to efficiency gains. The paper intends to convince the fresh produce industry that it is beneficial to invest in the infrastructure for automated data collection, whether it is barcode or RFID, since the majority of this industry does not have ANY automated data collection at all.

The data for our analysis was collected from cold storage facilities through interviews and surveys. Three major types of facilities participated in our study: those focusing on field packed product, facility packed product and local distribution centers, some of which do repack. Almost all major fresh produce commodities were observed in this study of 31 facilities. The facilities reside in all major regions of the U.S., and some import produce from Mexico, distribute in Canada, or pack in Hawaii and New Zealand.

\section{BACKGROUND}

There are three major groups of fresh produce facilities that could potentially benefit from greater automation in data collection along the supply chain. For the purposes of this study these groups are termed: distribution centers (DC), field packers (FLD), and facility packers (FAC). In commodity groups where the product is packed into cases in the field (FLD), the post harvest facility it arrives in is 
almost completely devoted to pre-cooling and storage. Precooling is the service of rapidly bringing the product to its ideal storage temperature in a manner that will minimize future spoilage without affecting product quality. These facilities are sometimes referred to as cooling sheds. The commodities packed in the field are often consistent in size.

Another group of facilities is focused on sorting and packing of product into cases (FAC). These facilities receive large bins full of heterogeneous product of the same variety from the field. Elaborate production lines sort the produce by quality and size so that the resulting case has some level of homogeneity. Camelo points out "To some extent, this is similar to a factory assembly line, where raw material from the field undergoes a sequence of activities resulting in the final packaged product."[2] Pre-cooling is usually simpler and it is often not as urgent as with the field packed product. These facilities are normally called packing houses.

Many FLD and FAC companies ship some or their product to other companies that sell or ship the product to final customers. These customers might be distribution centers of major retailers or distribution centers of companies that bring product closer to regional retailers by providing storage in that region. These facilities often repack product to specific store or customer requirements. We will broadly refer to these regional facilities as distribution centers (DCs).

Our 31 participants consisted of 18 FAC, 5 DCs and 8 FLD companies. They were divided into 2 groups: the group that performs automated data collection (ADC) and the group that performs manual data collection (MDC). The $\mathrm{ADC}$ and MDC groups have similar mixes of the three types of facilities described above.

\section{LITERATURE REVIEW}

Although Norman Woodland and Bernard Silver took out the first patent for bar-coding in 1949, barcodes really started seeing industrial use in 1981, when the Department of Defense adopted the use of Code 39 barcode sites Acord [3]. The Uniform Code Council's (UCC), now the GS1 US, has managed the barcode standards used throughout the U.S. and most of the world since 1970. This standard is now a part of the GS1 System. "The GS1 System - the world's most accepted standards system - standardizes identification numbers, Electronic Data Interchange (EDI), Business Message Standards using Extensible Mark-up Language (XML) and other supply chain solutions for more efficient business."[4]

In general, much is to be gained through these data collection technologies. Smith called Automatic Identification and Data Capture/collection (AIDC) systems one of the most widely used and under-recognized IT strategic assets in use in the global economy [5]. Singer [6] organizes the benefits of automatic data collection into three categories: 1. reducing time spent on data entry, 2. increasing the accuracy of maintenance information, and 3. reducing paperwork.

Extensive research has been conducted on the benefits of barcodes from the perspective of process engineering since its inception, but never specific to the fresh produce facilities this study addresses. The lack of research on the potential benefits of ADC specifically for this industry discourages this technological "upgrade." We believe that this study will raise the awareness of fresh produce companies to the benefits resulting from ADC adoption, in the form of barcode, RFID, or a combination of both technologies.

\section{Methodology}

\section{A. Metrics of Facility Efficiencies}

Our hypotheses imply that data collection contributes to improvements in labor costs, errors, and losses. The questions in the survey are therefore focused on these areas and organized by process steps within the facility, including receiving, processing/packing, storage, and shipping. Many questions attempt to approximate the amount of resources devoted to these process steps.

Another set of questions assesses the overall profile of the facility. There are questions about the total number of cases shipped, product mix, data collection methods, employee counts, and payroll related questions.

\section{B. Normalization}

Market prices fluctuate over time, and vary significantly among different commodities. Cost of services offered to different product types also fluctuate wildly. Therefore throughput (measured in number of pallets and cases) is used instead of revenue for normalization. Due to the significant differences in size among the participants, data is normalized for the calculation of performance measures.

\section{Results}

\section{A. Labor Productivity}

The labor devoted to processing outgoing orders (shipping), conducting inventory checks and especially carrying out all administrative activities was significantly lower in facilities that use barcodes compared with facilities that do not use barcode. This is summarized in Table I and Table II. 
TABLE I

MAN HOURS (MINUTES) A WEEK SPENT ON INVENTORY CHECKS ADC MDC

\begin{tabular}{|c|c|c|c|c|}
\hline \multirow{2}{*}{ Storage } & \multicolumn{4}{|c|}{ per pallet in storage } \\
\hline & \multicolumn{2}{|c|}{$\begin{array}{l}\text { per Case in a week } \\
(\mathrm{x} 1000)\end{array}$} & 5 & 18 \\
\hline \multirow{4}{*}{ Admin } & \multicolumn{4}{|c|}{$\begin{array}{c}\text { TABLE II } \\
\text { CASES SHIPPED PER EMPLOYEE }\end{array}$} \\
\hline & \multicolumn{3}{|c|}{$\mathrm{ADC}$} & $\mathrm{MDC}$ \\
\hline & annually (x1000) & \multicolumn{2}{|c|}{1800} & 285 \\
\hline & weekly (x1000) & \multicolumn{2}{|l|}{61} & 9 \\
\hline \multirow{2}{*}{ Shipping } & annually (x1000) & \multicolumn{2}{|l|}{477} & 275 \\
\hline & weekly (x1000) & \multicolumn{2}{|l|}{15} & 9 \\
\hline
\end{tabular}

\section{B. Inventory Checks}

Our survey reveals that a common reason to conduct an inventory check is the suspicion of a discrepancy between the records and the actual inventory. Amongst other benefits, a barcode reader prevents a mistype or misread of data. Therefore a facility that consistently captures transaction data using barcode readers will tend to have fewer discrepancies.

In order to normalize the effects of the larger inventory counts, we calculate the average total man hours devoted to this activity per week and divided by both the average cases shipped per week and the average capacity during peak season. We calculated both since many facilities have severe fluctuation in their throughput and inventory while others have a relatively steady activity during the operating season.

Data also suggests that the distribution centers devote more labor to inventory checks than post harvest facilities. This may be due to a much higher occurrence of mixed pallets and larger product mixes. A mixed pallet would require some degree of case level counting and the larger product mix complicates the counting.

Our results indeed show that ADC facilities conducted fewer checks per week and devoted significantly less manpower to this activity. At the DCs the difference between $\mathrm{ADC}$ and $\mathrm{MDC}$ facilities was particularly significant.

\section{Administrative Labor}

Another area of labor productivity improvement is Administrative Employees. The ADC group was able to ship over SIX times as many cases of product per administrative employee with the use of barcodes. MDC facilities with more advanced information systems (described below) performed better than ones with less advanced systems, but still had approximately twice the administrative costs as the ADC group.
Barcode-based facilities detract a pallet from inventory by scanning it. With non barcode systems, additional information must be entered into the information system, such as a 10-digit pallet number. Thus the majority of the administrative labor savings associated with barcode systems is due to the elimination pallet number typing and related errors. Lebow [7] points out that administrative staff makes one keyboarded data entry error for every 300 character strokes, while barcode scanning has less than one error in 39,000,000 characters. He also claim that while it takes about five seconds to handwrite six digits, one can scan 20 barcode digits in one [second].

Systems that do not use barcodes or pallet numbers have it rough! Since received shipments are often sent to numerous customers, the many relationships between received pallets or bins and their ultimate destination must be established, even when packed or repacked into different cases. This is often a complicated manual process. Most of these facilities store written receiving records and establish a relationship between the receiving ticket number and outgoing orders. When a quality concern dictates the unveiling of such information, significant administrative labor is invested in retrieving these records.

Administrative staff must also manage inventory data. Managing electronic documents is clearly easier than managing paper documents. And data retrieval, either for purposes of process improvement or produce traceability, is much easier if the documents are stored electronically.

In summary, our results indicate that appropriate software systems decrease the cost of administrative labor, and use of pallet barcode greatly increases the effectiveness of these systems.

\section{Shipping Labor}

Labor costs are also reduced for shipping processes, while throughput is increased. The average ADC shipping employee processed $73 \%$ more cases per week than the average MDC shipping employee. The difference was statistically significant with a confidence interval of $94.4 \%$.

Whether the pallets are scanned directly in front of the truck or if the smaller peel-off tags (A.K.A. daughter tags) are collected on the order sheet and scanned in the office, decrementing product from inventory is remarkably more efficient with the use of barcodes. Manual methods rely on the speed and accuracy at which an employee can count an order. The process is therefore slower and error-prone, and several employees are typically involved in confirming that the order is correct.

Shipping errors cause major revenue losses. When an order is barcode scanned during the shipping process, we observe that there is a very high probability of catching an error at or around the time the truck is loaded. Thus less effort is devoted to verifying the order is correct before it ships. Manual facilities must devote significantly more 
labor to verification.

\section{E. Capacity}

Data strongly suggests that more advanced information systems allow for greater use of a facility's total capacity and barcodes are virtually required to take full advantage of this improvement. As table III shows the MDC group used $55.6 \%$ of their maximum capacity during peak season while the ADC group used $66.3 \%$. Excluding the distribution centers, the effect of barcode was even greater.

TABLE III

AVERAGE PERCENTAGE OF MAX CAPACITY UTILIZED DURING PEAK SEASON

$$
\mathrm{ADC} \quad \mathrm{MDC}
$$

$\begin{array}{lll}\text { All } & 66.3 \% & 55.6 \% \\ \text { Excluding DCs } & 68.4 \% & 51.0 \%\end{array}$

MDC facilities utilize space less effectively since they must assign dedicated zones to various commodities. Otherwise forklift operators must spend extensive amounts of time searching for pallets of specific commodities. ADC facilities, on the other hand, can co-locate different products and have dynamic space allocation based on product mix, since pallet location data is available on the warehouse management system. In the more sophisticated ADC facilities the forklift operator uses a scanner to read barcodes on the pallet and on the rack or row, thus recording the relationship of pallet and location in the system with very little effort.

Most of the facilities in use today were designed when organizations packed few SKUs, and each commodity type had few packing options. Now a facility might pack for several retailers, each having unique containers and label. Going from a couple dozen SKUs to hundreds or thousands SKUs significantly increases the need for dedicated locations, resulting in lower space utilization.

\section{F. Spoilage Rate}

Another dimension of fresh produce inventory management is order picking according to harvest date data. Many participants rotate stock every night to be sure the oldest product is as easily accessible to the forklift operators as possible. In these instances, position not only dictates the SKU, but the date as well. When an organization has less faith in its inventory count, it is less inclined to mix by dates in the same row. Not only does this affect usable capacity as explained above, but it also requires labor devoted to repositioning pallets every night.

Many facilities, however, have too many SKUs or too much volume to separate product by date or rotate stock every night in such a way as to be sure the oldest product is easily identifiable. In these cases a detailed inventory management system is essential to reducing spoilage, by using FIFO when assigning stored pallets to customer orders.

As Table IV shows, the MDC group lost nearly eight times as many cases of product to spoilage caused by delay in storage.

TABLE IV

AVERAGE CASES LOST DUE TO DELAY PER 100,000 CASES SOLD

$\begin{array}{ll}\text { ADC } & \text { MDC } \\ 118 & 944\end{array}$

\section{CONCLUSIONS}

Our research indicates strong improvements in employee productivity in shipping, inventory counts, and especially administrative tasks with the use of automatic data collection.

Facilities using automatic data collection also had higher capacity utilization rates during peak season and lost significantly less product to spoilage.

For these reasons, we encourage fresh produce facilities to consider investing in automatic data collection systems, including identification technologies such as barcode and RFID.

\section{ACKNOWLEDGMENT}

The size and reach of the project would not have been possible with out the generous help of the Produce Reporter Company/Blue Book Services group and the generous support of RedLine Solutions.

Industry leaders that put in time above and beyond what was asked of are also in our debt. We especially thank Tom Casas VP IT and Mechanization and Frank Garcia Director of Distribution \& Cooling at Tanimura and Antle, Jack Brandt of Brandt Farms, Isaac Chapman of MTC, Kurt Harter of Orchard View Farms, Tim Farnsworth of Gingerich Farms, Chris Caratan of Columbine Vineyards, and Tom Clark of Sunny Cove Citrus. Many companies contributed significantly in addition to the 31 contributing hard data. We also thank Steve Teixeira at Frontier Cooling in Santa Maria, CA and Armand Cimino at Cimino Brothers Produce for their knowledge of the industry as a whole.

\section{REFERENCES}

[1] "Fact sheet on FDA's new food bioterrorism regulation: Establishment and maintenance of records" US Food and Drug Administration. December 2004; Revised November 2005

[2] A. F López Camelo,., Ph.D. "Manual for the preparation and sale of fruits and vegetables: From field to market" FAO AGRICULTURAL SERVICES BULLETIN 151 ISBN 92-5-104991-2

[3] T. Acord,. "Belly up to the barcode" FDM. Des Plaines: Aug 2003.Vol.75, Iss. 12; pg. 24

[4] “About GS1 US barcodes and eCom” GS1 US Web site. http://www.uccouncil.org/ean_ucc_system/about/about.html 
[5] Alan D Smith "Information management of automatic data capture: An overview of technical developments" Felix Offodile. Information Management \& Computer Security. Bradford: 2002.Vol.10, Iss. 2/3; pg. 109, 10 pgs

[6] Tom Singer. "The great data grab" IIE Solutions. Norcross: Dec 1998.Vol.30, Iss. 12; pg. 35, 4 pgs

[7] Jeff Lebow "Planning and implementing a successful barcode system: A project primer" IIE Solutions. Norcross: Feb 1998.Vol.30, Iss. 2; pg. 34, 6 pgs 